\title{
Saikosaponin D Isolated from Bupleurum falcatum Inhibits Selectin-Mediated Cell Adhesion
}

\author{
Myoung-Jun Jang ${ }^{1, \dagger}$, Ye Sol Kim ${ }^{2, \dagger}$, Eun Young Bae ${ }^{3}$, Tae-Seok Oh ${ }^{4}$, Hwa-Jung Choi ${ }^{5}$, \\ Jung-Hee Lee ${ }^{5}$, Hyun-Mee $\mathrm{Oh}^{2, *}$ and Seung Woong Lee ${ }^{6, *}$
}

1 Enviromental Agriculture Research Division, Gyeonggido Agricultural Reaearch and Extension Services(GARES), Hwaseong, Gyeonggi-do 445-784, Korea; E-Mail: jplant119@gmail.com

2 Bioindustial Process Research Center, Korea Research Institute of Bioscience and Biotechnology (KRIBB), Jeongeup-si, Jeollabuk-do 580-185, Korea; E-Mail: yesolkim@kribb.re.kr

3 LINC project group, University Industry Cooperation, Daejeon University, Daejeon 300-716, Korea; E-Mail: eunjs75@dju.kr

4 Department of Plant Resources, Kongju National University, Yesan 340-702, Korea;

E-Mail: ots1022@naver.com

5 Department of Beauty Science, Kwangju Women's University, Gwangju 506-713, Korea;

E-Mails: rerived@kwu.ac.kr (H.-J.C.); jh4471@kwu.ac.kr (J.-H.L.)

6 Department of Chemistry, Mokwon University, Daejeon 302-729, Korea

$\dagger$ These authors contributed equally to this work.

* Authors to whom correspondence should be addressed; E-Mails: ohhm@kribb.re.kr (H.-M.O.); 1swdoc@mokwon.ac.kr (S.W.L.); Tel.: +82-63-570-5233 (H.-M.O.); +82-42-829-7577 (S.W.L.); Fax: +82-42-829-7561 (S.W.L.).

External Editor: Isabel C. F. R. Ferreira

Received: 6 November 2014; in revised form: 2 December 2014 / Accepted: 2 December 2014 / Published: 4 December 2014

Abstract: Three saikosaponins were isolated from the $\mathrm{MeOH}$ extract of the roots of Bupleurum falcatum L.: saikosaponins B3 (1); B4 (2); and D (3). Of the three, compound 3 inhibited the interaction of selectins (E, L, and P) and THP-1 cells with $\mathrm{IC}_{50}$ values of 1.8, 3.0 and $4.3 \mu \mathrm{M}$, respectively. Also, the aglycone structure 4 of compound 3 showed moderate inhibitory activity on L-selectin-mediated cell adhesion. From these results, we suspect that compound $\mathbf{3}$ isolated from Bupleurum falcatum roots would be a good candidate for therapeutic strategies to treat inflammation. 
Keywords: Bupleurum falcatum L.; triterpenoid saponin; saikosaponin; selectin; cell adhesion molecules; anti-inflammatory agents

\section{Introduction}

The interactions between circulating leukocytes and vascular endothelial cells play an important role in the development of inflammatory diseases such as atherosclerosis, asthma, and rheumatoid arthritis [1,2]. Leukocyte trafficking is also an essential part of the immune response [3]. In general, cell to cell interactions are mediated by various cell adhesion molecules (ICAM-1, VCAM-1, and selectins), these ligands, cytokines, and chemokines. In particular, selectins are involved in the initial adhesive step in the recruitment and migration of immune cells to the inflammatory site [4,5]. The selectins have been categorized into three cell-surface glycoproteins: E-selectin, L-selectin, and P-selectin. The major ligand for P-selectin is P-selectin glycoprotein ligand-1 (PSGL-1, CD 162), constitutively expressed by leukocytes. It, together with CD44, can bind to E-selectin and L-selectin [6]. E-selectin and P-selectin are expressed on the cell-surface of endothelial cells by pro-inflammatory cytokines such as TNF- $\alpha$, IL-1 $\beta$, and IL-6 [7]. In contrast, L-selectin, which is present on leukocytes, is responsible for lymphocyte binding to endothelium and for the permeation of neutrophils in the inflammatory site stimulated by viruses and bacteria [8]. Selectins are also related to lymphocyte homing, chronic and acute inflammation processes including brain, lung, heart and skin inflammation, as well as cancer progression [1,2]. Therefore, blocking of selectins is considered a promising therapeutic approach for the prevention and treatment of inflammatory diseases, which are caused by the recruitment and infiltration of leukocytes.

Bupleurum falcatum L (B. falcatum, Apiaceae) is one of the most commonly used crude drugs in China and Korea. It was used as an important component of traditional oriental medicines for the treatment of chronic hepatitis and auto-immune diseases [9]. Saikosaponins, isolated from B. falcatum, are known to have numerous pharmacological activities including anti-inflammatory, anti-bacterial, anti-tumor, and anti-allergic activities [10-12]. We reported previously that the saikosaponins inhibited cell adhesion by VCAM-1/VLA-4 [13]. In the current study, we investigated the potent effect of saikosaponins, isolated from the $\mathrm{MeOH}$ extract of $B$. falcatum, on selectin-mediated cell adhesion.

\section{Results and Discussion}

\subsection{Isolation and Identification of Compounds 1-3}

During an investigation of selectin-mediated cell adhesion inhibitors obtained from natural sources, the $\mathrm{MeOH}$ extract of the roots of $B$. falcatum were observed to inhibit the interaction of selectin and THP-1 cells (data not shown). To isolate the active compounds with an inhibitory effect on the selectin/PSGL-1 interaction, the $\mathrm{MeOH}$ extract of the roots of $B$. falcatum was suspended in water and partitioned with $\mathrm{CHCl}_{3}$. The $\mathrm{CHCl}_{3}$-soluble fraction was separated on silica gel and ODS open-column chromatography, and then subjected to semi-preparative HPLC to yield compounds 1-3. Compound 3 was treated with an alcoholic alkali metal solution to preserve the epoxy moiety in the aglycone form 4 [14], and subsequently subjected to semi-preparative HPLC to yield 4. As shown in Figure 1, the 
structures were confirmed as saikosaponins B3 (1), B4 (2), and D (3) and also saikosapogenin G (4) through NMR and MS spectra analyses, and comparison with published data [14-17].

Figure 1. Chemical structures of compounds 1-4.

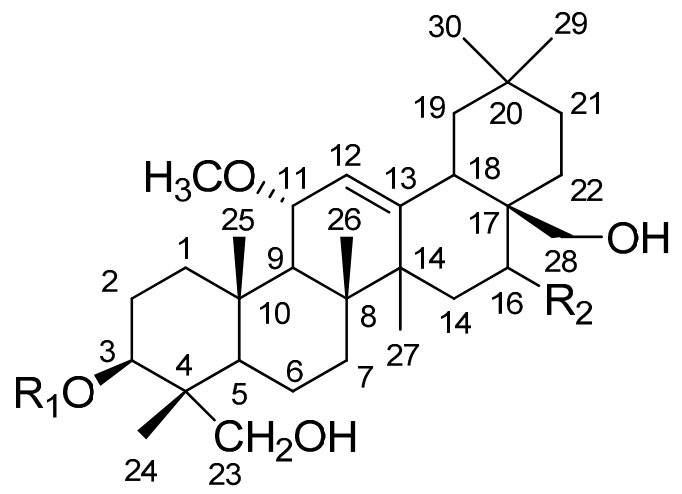

$\mathrm{R}_{1} \quad \mathrm{R}_{2}$

1: Saikosaponin B3 Glc-Fuc- $\quad \beta-\mathrm{OH}$

2: Saikosaponin B4 Glc-Fuc- $\quad \alpha-\mathrm{OH}$

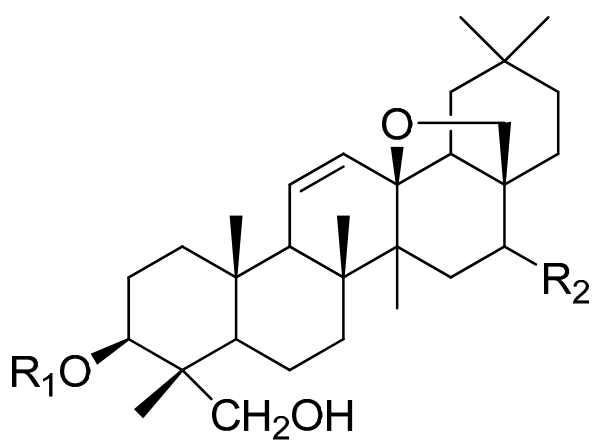

$\begin{array}{ll}\mathrm{R}_{1} & \mathrm{R}_{2}\end{array}$

3: Saikosaponin D

Glc-Fuc- $\quad \alpha-\mathrm{OH}$

4: Saikosapogenin G H

$\alpha-\mathrm{OH}$

\subsection{Cell Adhesion Inhibitory Activities}

2.2.1. Inhibitory Effects of Compounds 1-4 on Selectins (E, L, and P)-Mediated Cell Adhesion Activities in Vitro

The effects of compounds 1-3 on the binding between THP-1 cells and recombinant E-selectin, L-selectin, and P-selectin (R\&D Systems, Minneapolis, MN, USA), were tested using a modified ELISA method [13]. Briefly, fluorescence-labeled THP-1 cells were added to selectin-coated plates in the presence or absence of the compounds for $1 \mathrm{~h}$ at $37^{\circ} \mathrm{C}$. After then, fluorescent intensity of THP-1 cells adhered on selectin were measured. Compound 3 inhibited direct binding between E-selectin and THP-1 cells in a dose-dependent manner, with an $\mathrm{IC}_{50}$ value of $1.8 \mu \mathrm{M}$ (Figure 2). Compounds 1 and $\mathbf{2}$ did not show any inhibitory activity in the cell adhesion assay $(<10 \%$ at $10 \mu \mathrm{M}$, Figure 2$)$. These compounds were examined further to determine if they could affect binding between the cells and other selectins such as L-selectin and P-selectin. Compound $\mathbf{3}$ also showed inhibitory activity on cell adhesion mediated by L-selectin and P-selectin in a dose dependent manner with an $\mathrm{IC}_{50}$ value of $3.0 \mu \mathrm{M}$ and $4.3 \mu \mathrm{M}$ (Figure 2), respectively. However, the other compounds (1 and 2) showed no inhibitory effects on the cell adhesion similar to the result with E-selectin $(<10 \%$ at $10 \mu \mathrm{M}$, Figure 2$)$. THP-1 or HL-60 cells did not attach on non-coated plate while the cells adhered on selectin-coated plate, suggesting that it is a specific interaction mediated by selectin. 
Figure 2. Inhibitory effects of compounds 1-4 on the cell adhesion on E-, L-, P-selectin. BCECF-AM-labeled THP-1 cells and test compounds 1-4 were added to 96-well plates coated with E-selectin, L-selectin, and P-selectin, respectively. After incubation for $1 \mathrm{~h}$ at $37^{\circ} \mathrm{C}$, cells were dissolved in 1\% Triton X-100 in PBS, and fluorescent intensity was measured as described in the Experimental section. The data are presented as the means of three independent experiments performed in duplicate.

THP-1 cell adhesion to E-selectin

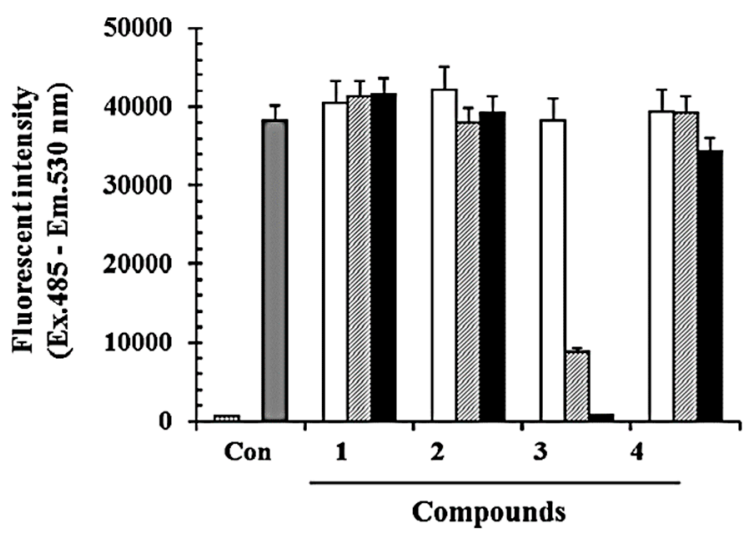

THP-1 cell adhesion to $\mathbf{P}$-selectin

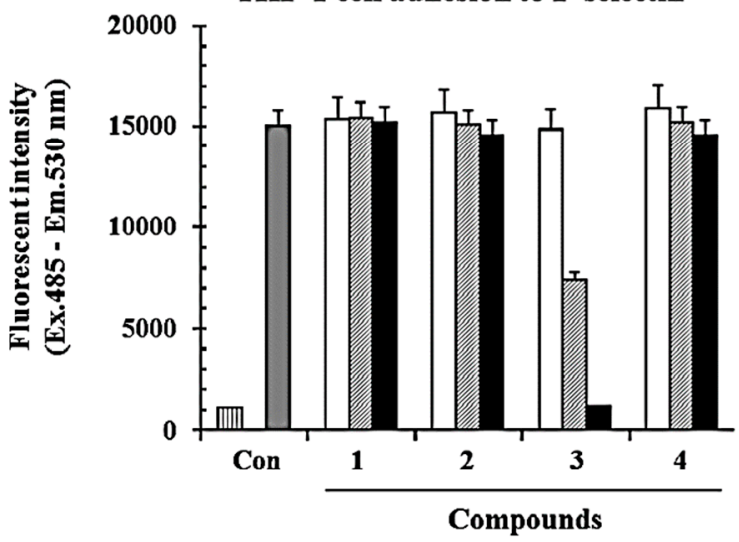

THP-1 cell adhesion to L-selectin

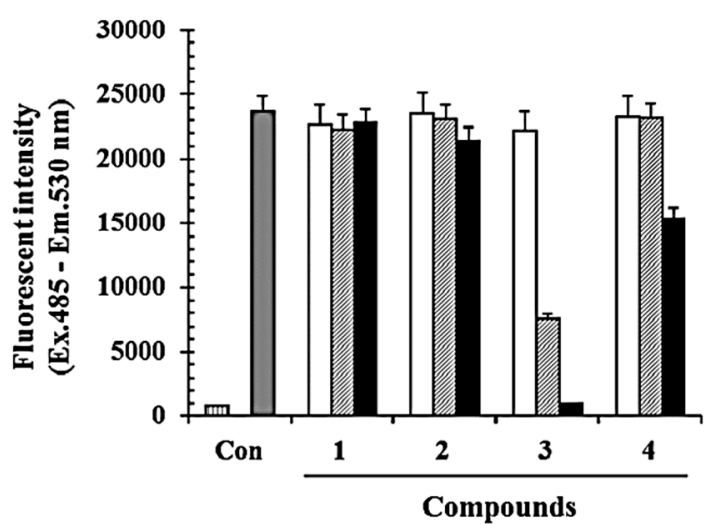

血 Non-coated + cells

$\square$ Selectin-coated + cells $(\mathbf{S}+\mathbf{C})$

$\square \mathbf{S}+\mathbf{C}+\mathbf{1} \boldsymbol{\mu M}$ treated

诸 $\mathbf{S}+\mathbf{C}+3 \mu \mathrm{M}$ treated

$\mathbf{S}+\mathbf{C}+10 \mu \mathrm{M}$ treated

In addition, as compound 3 lacked cytotoxic effects on THP-1 cells at the concentrations employed in this study, it was investigated even further to confirm that the inhibitory activity was not due to cytotoxic action. As shown in Figure 3, compound $\mathbf{3}$ exhibited $65 \%$ cell viability at the concentration of $10 \mu \mathrm{M}$, and did not show any cytotoxicity at the other concentrations used in this study.

As shown in Figures 1 and 2, compounds 1 and 2, which possess methoxy and hydroxymethyl groups in addition to two sugar moieties, had no inhibitory effects on the direct binding between the selectins and THP-1 cells. However, compound 3, containing an epoxy group and two sugar moieties, showed potent inhibitory activities compared to compounds $\mathbf{1}$ and $\mathbf{2}$ in this assay. This result suggested that the presence of the epoxy group may affect cell adhesion inhibitory activity. In particular, we tested whether the aglycone 4 , which lacked the two sugar moieties of compound $\mathbf{3}$, showed the same inhibitory activity in the binding between selectins (E, L, and P) and THP-1 cells. Compound 4 showed 40\% inhibitory activity in the cell adhesion assay with L-selectin at a concentration of $10 \mu \mathrm{M}$, and it still had moderate activity compared with compound 3. However, it only showed $20 \%$ and $10 \%$ inhibitory activities at a 
concentration of $10 \mu \mathrm{M}$ in assays with E-selectin and P-selectin, respectively. This result suggested that the presence of the sugar moieties could affect the cell adhesion inhibitory activity.

Figure 3. Effect of compounds 1-4 on THP-1 cell viability. Cells were incubated with the indicated concentrations of compounds 1-4 for $48 \mathrm{~h}$. The viability was determined by the MTT-based cytotoxicity assay. The \% viability was calculated as follows: (absorbance for compound treated cells / absorbance for untreated cells $) \times 100$. Data are presented as the mean $\pm \operatorname{SE}(n=3)$.

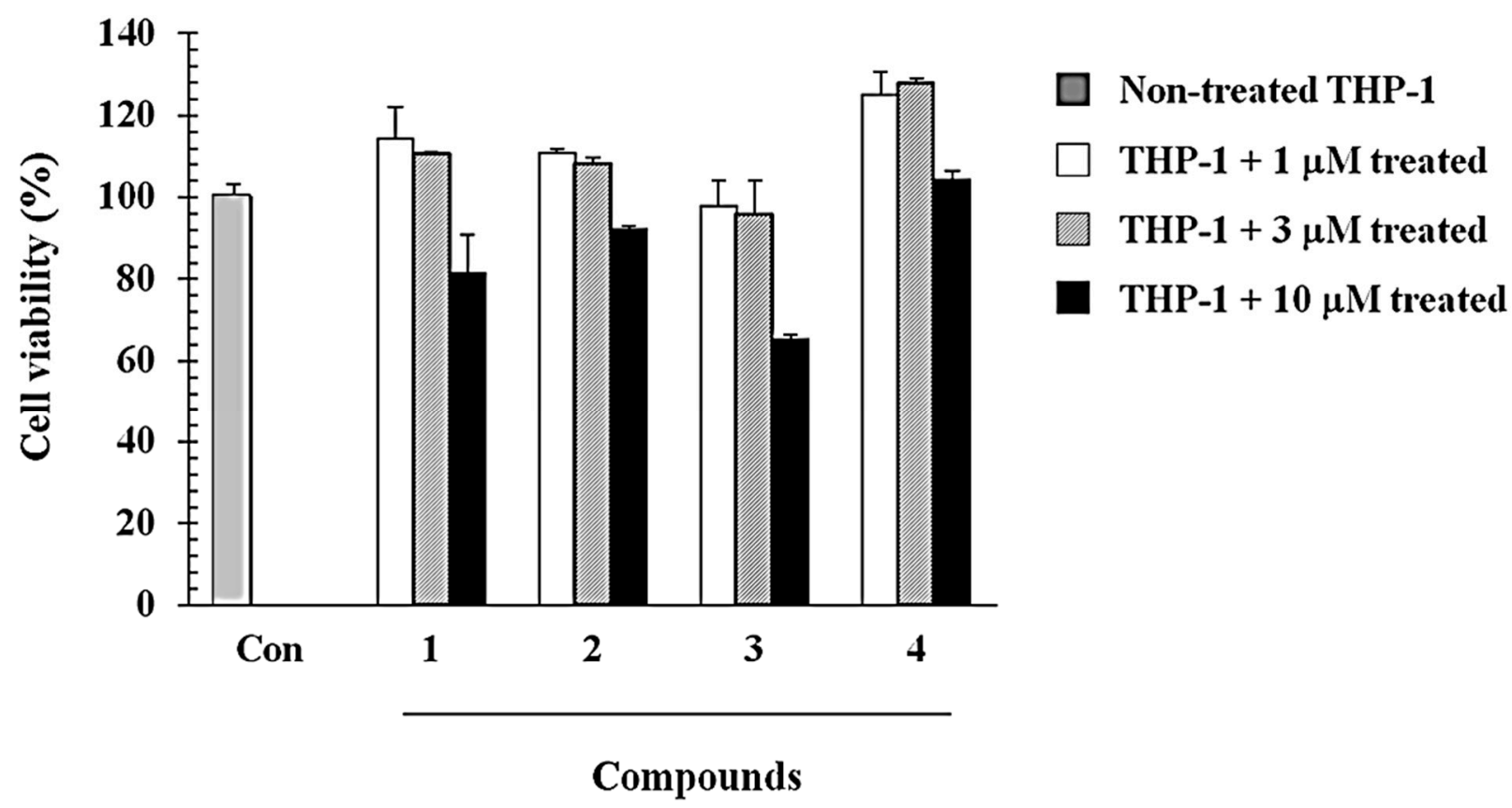

\subsubsection{Compound 3 Inhibits Monocyte Adhesion onto Endothelial Cells Activated by TNF- $\alpha$}

We further investigated whether compounds $\mathbf{3}$ and $\mathbf{4}$ were able to modulate cell to cell interaction using a monocyte-endothelial cell adhesion assay. HUVEC cells were stimulated with TNF- $\alpha(5 \mathrm{ng} / \mathrm{mL})$ for $6 \mathrm{~h}$ prior to the addition of THP-1 cells. THP-1 cells were incubated with or without compounds 3 and 4 at various concentrations (final concentrations of 1,5 , and $10 \mu \mathrm{M}$ ) for $30 \mathrm{~min}$, and then added onto HUVEC cells activated with TNF- $\alpha$. As shown in Figure 4, compound 3 significantly inhibited the THP-1 adhesion to the HUVECs monolayer in a concentration dependent manner. The inhibition of monocyte-endothelial cell adhesion was showed as more than $95 \%$ at the concentrations of $5 \mu \mathrm{M}$ and $10 \mu \mathrm{M}$ (Figure 4). However, compound 4 failed to inhibit the adhesion as shown in Figure 4, suggesting that the presence of the sugar moieties could affect the cell adhesion inhibitory activity.

\subsubsection{Compound $\mathbf{3}$ Inhibits TNF- $\alpha-$ Induced Cell Adhesion Molecule Expression in Monocytes}

Compound $\mathbf{3}$ showed potent inhibitory activities on the cell adhesion assay using three recombinant proteins (E-selectin, L-selectin, and P-selectin) and monocytes. This can be a means that compound 3 inhibits direct binding between selectins and their ligands expressed on monocytes. Alternatively, this compound can be inhibits monocyte adhesion through the reduction of the expression of selectin ligand. Therefore, we investigated here the effect of compound $\mathbf{3}$ on expression of P-selectin ligand 
(PSGL-1/CD162) in THP-1 cells by FACS analysis (Figure 5). Isotype control antibody used for control. CD162 expression was significantly reduced by the treatment with compound 3 relative to vehicle in a time dependent manner ( $40 \%$ and $35 \%$ of control at $30 \mu \mathrm{M}$ for $1 \mathrm{~h}$ and $6 \mathrm{~h}$, respectively), it suggesting this compound partially regulate the cell adhesion through the regulation of the selectin ligand expression.

Figure 4. Inhibitory effects of compounds 3 and 4 on THP-1 monocyte adhesion to HUVECs. HUVECs were incubated with $5 \mathrm{ng} / \mathrm{mL} \mathrm{TNF-} \alpha$ in the absence or presence of compounds 3 and $4(1,5$, and $10 \mu \mathrm{M})$. Fluorescence-labeled THP-1 cells were added to the HUVECs and allowed to incubate for $1 \mathrm{~h}$. The fluorescent intensity was measured as described in the Experimental Section. The data are presented as the means of three independent experiments performed in duplicate.

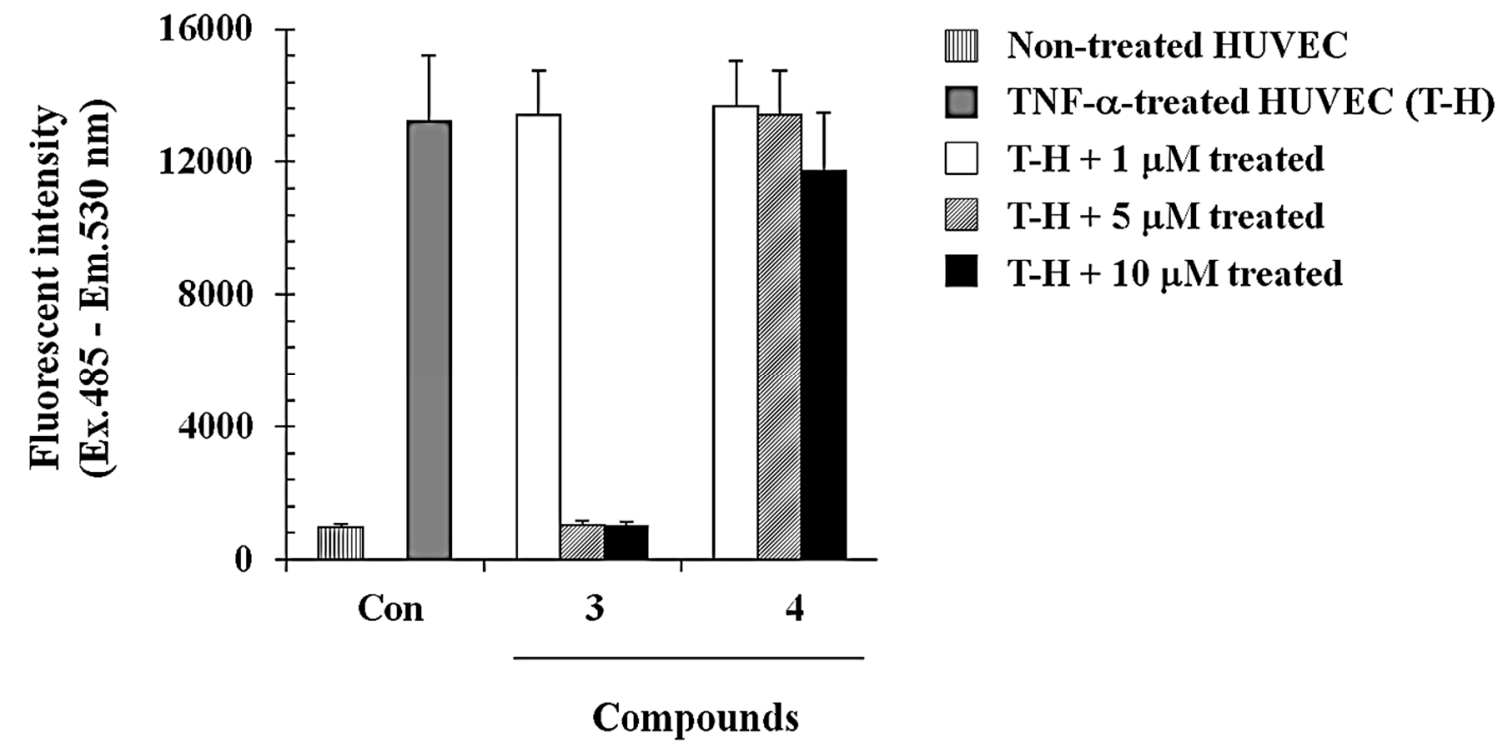

Figure 5. Compound 3 inhibits the expression of P-selectin ligand (CD162) in THP-1 cells. THP-1 cells were incubated with compound $3(30 \mu \mathrm{M})$ for 1 and $6 \mathrm{~h}$ and then CD162 expression was analyzed by FACS. (a) An overlay FACS histogram of THP-1 cells stimulated with compound 3 for $6 \mathrm{~h}$ and (b) mean fluorescence intensity were shown.

(a)

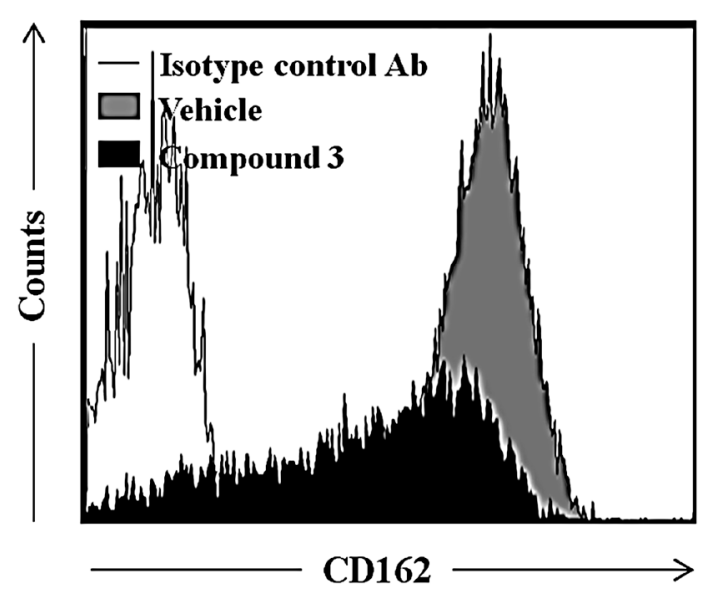

(b)

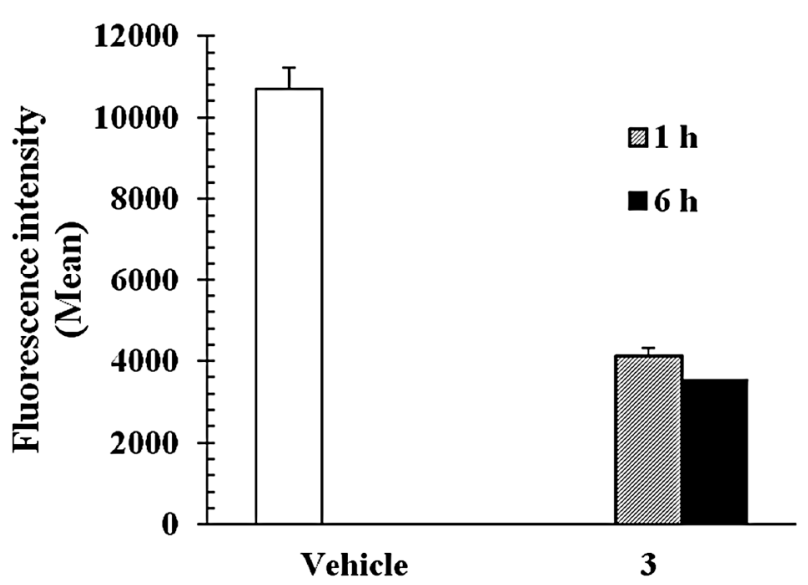




\section{Experimental Section}

\subsection{Plant Material, Extraction and Isolation}

The B. falcatum roots were purchased at an herbal market in Daejeon, Korea. A voucher specimen (PBC-247A) was deposited in the Korea Plant Extract Bank, at the Korea Research Institute of Bioscience and Biotechnology. The dried roots of the B. falcatum $(2.4 \mathrm{~kg}$ ) were extracted with $\mathrm{MeOH}(10 \mathrm{~L})$ for 7 days at room temperature. The $\mathrm{MeOH}$ extract was evaporated in vacuo, yielding a residue ( $435 \mathrm{~g})$. The residue was suspended in distilled water $(2 \mathrm{~L})$ and extracted with $\mathrm{CHCl}_{3}(8 \mathrm{~L})$. The $\mathrm{CHCl}_{3}$ layers were then evaporated in vacuo, with the resulting extract (180 g) subjected to silica gel (230-400 mesh, $1.8 \mathrm{~kg}$, Merck KGaA, Darmstadt, Germany) column chromatography using a gradient of $\mathrm{CHCl}_{3}-\mathrm{MeOH}(100: 0$, 90:1, 70:1, 50:1, 30:1, 15:1, 5:1, 1:1; each 3.0 L, v/v). Based on the TLC profile, 19 fractions (F1-F19) were collected, with each fraction monitored by an in vitro cell adhesion inhibitory assay. Fraction F18 (15 g) showed the highest inhibitory effect and was subjected to reverse-phase column chromatography $(300 \mathrm{~g})$, then eluted with $\mathrm{MeOH}-\mathrm{H}_{2} \mathrm{O}(70: 30,80: 20,90: 10,100: 0$; each $2.0 \mathrm{~L}$, v/v), to yield 11 subfractions (F18-1-F18-11), based on the TLC profile. In addition, F18-3 (680 mg) was successively separated by semi-preparative HPLC $\left(\mathrm{MeOH}-\mathrm{H}_{2} \mathrm{O}, 65: 35\right.$, v/v), yielding 1 (19 mg), and 2 (18 mg). Fraction F18-4 (687 mg) was successively separated by semi-preparative HPLC (YMC-pack ODS-H80, $4 \mu \mathrm{m}, 250 \times 20 \mathrm{~mm}$, flow rate $5.0 \mathrm{~mL} / \mathrm{min})$ and elution with $\mathrm{MeOH}-\mathrm{H}_{2} \mathrm{O}(65: 35$, v/v), yielding $3(18 \mathrm{mg})$. Compound 3 (70 mg) was dissolved in butanol $(10 \mathrm{~mL})$, followed by addition of sodium metal (350 $\mathrm{mg})$. This mixture was allowed to react for $6 \mathrm{~h}$ at $80{ }^{\circ} \mathrm{C}$. Water was then added to stop the reaction. The butanol layer was washed with water three times and evaporated to dryness. The residue was then separated by semi-preparative HPLC $\left(\mathrm{MeOH}-\mathrm{H}_{2} \mathrm{O}, 75: 25\right.$, v/v), yielding 4 (15 mg).

\subsection{Cell Adhesion to E-Selectin, L-Selectin, and P-Selectin}

The Human acute monocytic leukemia cell line THP-1 was maintained in RPMI 1640, supplemented with $10 \%$ fetal calf serum, $100 \mathrm{U} / \mathrm{mL}$ penicillin and $100 \mu \mathrm{g} / \mathrm{mL}$ streptomycin sulfate. These cell lines were maintained at $37^{\circ} \mathrm{C}$ in a humidified incubator containing $5 \% \mathrm{CO}_{2}$. An adhesion assay using soluble E-selectin, L-selectin, and P-selectin and THP-1 cells was performed as described previously with slight modifications. 96-well plates were coated with $100 \mu \mathrm{L}$ of recombinant E-selectin, L-selectin, and P-selectin (R\&D systems) at a concentration of $5 \mu \mathrm{g} / \mathrm{mL}$ in PBS at $37^{\circ} \mathrm{C}$ for $3-4 \mathrm{~h}$. The wells were then washed twice with PBS and blocked by addition of $200 \mu \mathrm{L}$ of PBS with $1 \%$ BSA and incubation for $1 \mathrm{~h}$ at room temperature. For fluorescent labeling of THP-1 cells, $1 \times 10^{6}$ cells washed once in RPMI 1640 were re-suspended in $12 \mathrm{~mL}$ of RPMI 1640 containing $2 \mu \mathrm{M}$ BCECF-AM (2',7'-bis-2-carboxyethyl-5-(6)carboxyfluorescein acetoxymethyl ester), incubated at $37{ }^{\circ} \mathrm{C}$ for $1 \mathrm{~h}$, and washed once with RPMI 1640/0.1\% fetal bovine serum. Next, fluorescent-labeled THP-1 cells and $5 \mu \mathrm{L}$ of compounds $\mathbf{1}-\mathbf{4}$ were added to each well. The plates were incubated for $1 \mathrm{~h}$ at $37^{\circ} \mathrm{C}$ and the wells gently washed once with RPMI 1640/0.1\% fetal bovine serum. Fluorescent intensity was measured with a fluorescent plate reader (FL $\times 800 \mathrm{TM}$, BioTek $^{\circledR}$ Instruments, Inc., Winooski, Vermont, USA) at an excitation wavelength of $485 \mathrm{~nm}$ and an emission wavelength of $530 \mathrm{~nm}$. 


\subsection{Cell Adhesion to HUVEC}

HUVECs in $150 \mu \mathrm{L}$ complete growth medium were seeded onto 96-well plates at $1 \times 10^{4}$ cells per well and incubated to confluency overnight at $37^{\circ} \mathrm{C}$. Next, the HUVECs monolayer was stimulated with $5 \mathrm{ng} / \mathrm{mL}$ TNF- $\alpha$ (Sigma-aldrich, St. Louis, Missouri, USA) for $4 \mathrm{~h}$. Then, fluorescent-labeled THP-1 cells and $5 \mu \mathrm{L}$ of compound 3 were then added to each well. The plates were incubated for $1 \mathrm{~h}$ at $37^{\circ} \mathrm{C}$ and the wells were gently washed once with RPMI 1640/0.1\% fetal bovine serum. Fluorescent intensity was measured with a fluorescent plate reader at an excitation wavelength of $485 \mathrm{~nm}$ and an emission wavelength of $530 \mathrm{~nm}$.

\subsection{Cell Adhesion Molecule Expression on THP-1 Cells}

The cell surface expression of P-selectin on THP-1 cells was further confirmed by flow cytometry. Briefly, THP-1 cells were incubated with or without compound 3 for $2 \mathrm{~h}$ followed by TNF- $\alpha(5 \mathrm{ng} / \mathrm{mL})$. P-selectin was measured $4 \mathrm{~h}$ after TNF- $\alpha$ treatment. The cells were washed with PBS and dislodged, then incubated with anti-human CD162 (PSGL-1) or control IgG antibody $\left(1.0 \mathrm{mg} / 10^{6}\right.$ cells, $30 \mathrm{~min}, 4^{\circ} \mathrm{C}$ ). After incubation, the cells were washed with PBS and stained with FITC conjugated goat anti-human IgG for $30 \mathrm{~min}$ at $4{ }^{\circ} \mathrm{C}$. Finally, the cells were fixed with $1.0 \%$ paraformaldehyde and analyzed for the expression of cell adhesion molecules using a flow cytometer (FACSArial II, BD Biosciences, San Jose, CA, USA). For each sample, 20,000 events were acquired. Analysis was carried out using FACSDiva software Version 6.1.2 (BD Biosciences). The auto-fluorescence intensity was subtracted from the treated conditions. Mean fluorescence intensity was estimated from three independent experiments and bar diagrams were plotted.

\subsection{Cell Viability Assay}

Cell viability was assessed by morphology and by reduction of the tetrazolium salt (MTT) as previously described [18]. Briefly, the THP-1 cells $\left(2 \times 10^{5}\right.$ cells/well $)$ and various concentrations of compounds 1-4 were added to the 96 -well plates, incubated for $48 \mathrm{~h}$ at $37^{\circ} \mathrm{C}$, and $5 \mu \mathrm{L}$ of MTT solution $\left(5 \mathrm{mg} / \mathrm{mL}\right.$ in PBS) was added to each well of the 96-well plates. After incubation for $4 \mathrm{~h}$ at $37{ }^{\circ} \mathrm{C}$, the absorbance was measured at $540 \mathrm{~nm}$ using a microplate reader (Bio-Rad, Hercules, CA, USA) with the reference absorbance at $650 \mathrm{~nm}$.

\section{Conclusions}

In conclusion, three saikosaponins 1-3 were isolated from the $\mathrm{MeOH}$ extract of Bupleurum falcatum roots. Among them, compound $\mathbf{3}$ showed the highest potency in the assay system using recombinant proteins (E-selectin, L-selectin, and P-selectin). The aglycone structure $\mathbf{4}$ of compound $\mathbf{3}$ showed mild inhibitory activity on cell adhesion assay using L-selectin. In particular, compound $\mathbf{3}$ successfully inhibited monocyte adhesion to endothelial cells and reduce the expression of P-selectin ligand on THP-1 cells. These results could be useful for the design of new cell adhesion inhibitors for anti-inflammatory agents. 


\section{Acknowledgments}

This research was supported by Basic Science Research Program through the National Research Foundation of Korea (NRF) funded by the Ministry of Science, ICT \& Future Planning (NRF-2014R1A1A1006091).

\section{Author Contributions}

Conceived and designed the experiments: S.W.L. and H.-M.O.; Performed the experiments: M.-J.J., Y.S.K., and E.Y.B.; Analyzed the data: S.W.L., H.-M.O., T.-S.O, J.-H.L, H.-J.C., and E.Y.B.; Wrote the paper: S.W.L. and H.-M.O.; All authors read and approved the final manuscript.

\section{Conflicts of Interest}

The authors declare no conflict of interest.

\section{References}

1. Springer, T.A. Traffic signals for lymphocyte recirculation and leukocyte emigration: the multistep paradigm. Cell 1994, 76, 301-314.

2. Vanderslice, P.; Biediger, R.J.; Woodside, D.G.; Berens, K.L.; Holland, G.W.; Dixon, R.A. Development of cell adhesion molecule antagonists as therapeutics for asthma and COPD. Pulm. Pharmacol. Ther. 2004, 17, 1-10.

3. Auvinen, K.; Jalkanen, S.; Salmi, M. Expression and function of endothelial selectins during human development. Immunology 2014, 143, 406-415.

4. Patel, K.D.; Cuvelier, S.L.; Wiehler, S. Selectins: Critical mediators of leukocyte recruitment. Semin. Immunol. 2002, 14, 73-81.

5. Ley, K.; Laudanna, C.; Cybulsky, M.I.; Nourshargh, S. Getting to the site of inflammation: The leukocyte adhesion cascade updated. Nat. Rev. Immunol. 2007, 3, 678-689.

6. Kansas, G.S. Selectins and their ligands: Current concepts and controversies. Blood 1996, 88, 3259-3287.

7. Ley, K. The role of selectins in inflammation and disease. Trends Mol. Med. 2003, 9, 263-268.

8. Arbones, M.L.; Ord, D.C.; Ley, K.; Ratech, H.; Maynard-Curry, C.; Otten, G.; Capon, D.J.; Tedder, T.F. Lymphocyte homing and leukocyte rolling and migration are impaired in L-selectindeficient mice. Immunity 1994, 1, 247-260.

9. Yamada, H.; Sun, X.B.; Matsumoto, T.; Ra, K.S.; Hirano, M.; Kiyohara, H. Purification of anti-ulcer polysaccharides from the roots of Bupleurum falcatum. Planta Med. 1991, 57, 555-559.

10. Park, K.H.; Park, J.; Koh, D.; Lim, Y. Effect of Saikosaponin-A, a Triterpenoid Glycoside, Isolated from Bupleurum falcatum on Experimental Allergic Asthma. Phytother. Res. 2002, 16, 359-363.

11. Sun, Y.; Cai, T-.T.; Zhou, X-.B.; Xu, Q. Saikosaponin a inhibits the proliferation and activation of T cells through cell cycle arrest and induction of apoptosis. Int. Immunopharmacol. 2009, 9, 978-983.

12. Leung, C.Y.; Liu, L.; Wong, R.N.S.; Zeng, Y.Y.; Li, M.; Zhou, H. Saikosaponin-d inhibits T cell activation through the modulation of $\mathrm{PKC} \theta$, JNK, and NF- $\mathrm{KB}$ transcription factor. Biochem. Biophys. Res. Commun. 2005, 338, 1920-1927. 
13. Lee, S.W.; Kim, M.S.; Lim, J.H.; Chang, J.S.; Ling, J.; Bae, K.H.; Lee, W.S.; Rho, M.C. Inhibition of VLA-4/VCAM-1-mediated Cell Adhesion by Triterpenoid Saponins from Bupleurum falcatum L. Bull. Korean Chem. Soc. 2010, 31, 1931-1936.

14. Nose, M.; Amagaya, S.; Takeda, T.; Ogihara, Y. New derivatives of saikosaponin c. Chem. Pharm. Bull. 1989, 37, 1293-1296.

15. Ishii, H.; Nakamura, M.; Seo, S.; Tori, K.; Tozyo, T.; Yoshimura, Y. Isolation, characterization, and nuclear magnetic resonance spectra of new saponins from the roots of Bupleurum falcatum L. Chem. Pharm. Bull. 1980, 28, 2367-2383.

16. Tori, K.; Seo, S.; Yoshimura, Y.; Nakamura, M.; Yutaka, T.; Ishii, H. Carbon-13 NMR spectra of saikosaponin A, C, D and F isolated from Bupleurum falcatum L. Tetrahedron Lett. 1976, 46, 4167-4170.

17. Kuboata, T.; Hinoh, H. The constitution of saponins isolated from Bupleurum falcatum L. Tetrahedron Lett. 1967, 9, 303-306.

18. Mosmann, T. Rapid colorimetric assay for cellular growth and survival: Application to proliferation and cytotoxicity assays. J. Immunol. Methods 1983, 65, 55-63.

Sample Availability: Not available.

(C) 2014 by the authors; licensee MDPI, Basel, Switzerland. This article is an open access article distributed under the terms and conditions of the Creative Commons Attribution license (http://creativecommons.org/licenses/by/4.0/). 